\title{
Early Detection of Critical IIIness Outside the Intensive Care Unit: Clarifying Treatment Plans and Honoring Goals of Care Using a Supportive Care Team
}

\author{
Russ Granich, MD ${ }^{1 *}$, Zoe Sutton, RN, MSN, PNP¹, Yan S. Kim, MD, PhD², Megan Anderson, MD³, Helen Wood, MS, RN¹,
} John E. Scharf, MD³, Arona Ragins, MA², Gabriel J. Escobar, MD²

\begin{abstract}
${ }^{1}$ Kaiser Permanente South San Francisco Medical Center, South San Francisco, California; ${ }^{2}$ Systems Research Initiative, Division of Research, Kaiser Permanente Northern California, Oakland, California; ${ }^{K}$ Kaiser Permanente Sacramento Medical Center, Sacramento, California.
\end{abstract}

\begin{abstract}
Given the high mortality experienced by patients who deteriorate outside the intensive care unit, issues related to patient preferences around escalation of care are common. However, the literature on early warning systems (EWSs) provides limited information on how respecting patient preferences can be incorporated into clinical workflows. In this report, we describe how we developed workflows for integrating supportive care with an automated EWS in the context of a 2-hospital pilot. We used the Institute for Healthcare Improvement's Plan-Do-Study-Act approach to achieve consensus with clinicians and administrators. The
\end{abstract}

workflows will serve as the basis for dissemination to an additional 19 hospitals. We were successful in integrating an automated EWS with supportive care. Our workflows take local resource availability into account and have been well received by hospitalists, nurses, and families. Our work demonstrates that one can achieve integration of proactive supportive care into the operation of an EWS. Creation of a palliative care response arm that is complementary to a clinical rescue arm ensures that patient preferences are respected. Journal of Hospital Medicine 2016;11:S40-S47. (C) 2016 Society of Hospital Medicine
The likelihood of meaningful survival after cardiopulmonary arrest is low and even lower the longer the patient has been in the hospital ${ }^{1,2}$; realization of this ${ }^{3}$ played a major role in the development of rapid response teams (RRTs). ${ }^{4}$ As noted elsewhere in this journal, the limited success of these teams ${ }^{5-7}$ has inspired efforts to develop systems to identify patients at risk of deterioration much earlier.

Whereas a number of recent reports have described end-of-life care issues in the context of RRT operations ${ }^{8-16}$ descriptions of how one might incorporate respecting patient preferences into development of a response arm, particularly one meant to scale up to a multiple hospital system, are largely absent from the literature. In this article, we describe the implementation process for integrating palliative care and the honoring of patient choices, which we refer to as supportive care, with an automated early warning system (EWS) and an RRT.

The context of this work is a pilot project conducted at 2 community hospitals, the Kaiser Permanente Northern California (KPNC) Sacramento (200 beds) and South San Francisco (100 beds) medical

\footnotetext{
*Address for correspondence and reprint requests: Russ Granich, MD, South San Francisco Kaiser Permanente, 1200 El Camino Real, South San Francisco, CA 94080; Telephone: 650-827-6361; Fax: 650-8276356; E-mail: russ.granich@kp.org

Additional Supporting Information may be found in the online version of this article.

Received: March 11, 2016; Revised: September 6, 2016; Accepted: September 11, 2016

2016 Society of Hospital Medicine DOI 10.1002/jhm.2660

Published online in Wiley Online Library (Wileyonlinelibrary.com).
}

centers. Our focus was to develop an approach that could serve as the basis for future dissemination to the remaining $19 \mathrm{KPNC}$ hospitals, regardless of their size. Our work incorporated the Respecting Choices mod$\mathrm{el},{ }^{17}$ which has been endorsed by KPNC for all its hospitals and clinics. We describe the workflow we developed to embed the supportive care team's (SCT) reactive and proactive components into the EWS response arm. We also provide a granular description of how our approach worked in practice, as evidenced by the combined patient and provider experiences captured in 5 vignettes as well as some preliminary data obtained by chart review

When patients arrive in the hospital, they may or may not have had a discussion about their care escalation and resuscitation preferences. As noted by Escobar and Dellinger ${ }^{18}$ elsewhere in this issue of the Journal of Hospital Medicine, patients with documented restricted resuscitation preferences (eg, do not resuscitate [DNR] or partial code) at the time of admission to the hospital account for slightly more than half of the hospital deaths at 30 days after admission. In general, these stated preferences are honored.

Significant proportions of patients are unstable at the time of admission or have a significant underlying chronic illness burden predisposing them to unexpected deterioration. Often these patients lose decisionmaking capacity when their condition worsens. We need to ensure we honor their wishes and identify the correct surrogate.

To make sure a patient's wishes are clear, we developed a workflow that included 2 components. One component is meant to ensure that patient preferences 
are honored following a EWS alert. This allows for contingencies, including the likelihood that a physician will not be available to discuss patient wishes due to clinical demands. Although it may appear that the role of the hospitalist is supplanted, in fact this is not the case. The only person who has authority to change a patient's code status is the hospitalist, and they always talk to the patient or their surrogate. The purpose of the teams described in this report is to provide backup, particularly in those instances where the hospitalist is tied up elsewhere (eg, the emergency department). Our workflows also facilitate the integration of the clinical with the palliative care response. The other component employs the EWS's ancillary elements (provision of a severity of illness score and longitudinal comorbidity score in real time) to screen patients who might need the SCT. This allows us to identify patients who are at high risk for deterioration in whom an alert has not yet been issued due to acute instability or comorbid burden (leading to high probability of unexpected deterioration) or both and who do not have stated goals of care and/or an identified surrogate.

\section{IMPLEMENTATION APPROACH}

We developed our workflow using the Institute for Healthcare Improvement's Plan-Do-Study-Act approach. ${ }^{19,20}$ Our first finding was that most alerts did not require a rapid intervention by the SCT. Both sites reserved time in the SCT physicians' schedule and considered changing staffing levels (the smaller site only had funding for physician support 20 hours per week), but neither had to make such changes. One reason for this was that we increased social worker availability, particularly for off hours (to cover the contingency where an alert was issued in the middle of the night while the on-call hospitalist was handling an admission in the emergency department). The second was that, as is described by Escobar et al., ${ }^{21}$ the EWS provides a risk of deterioration in the next 12 hours (as opposed to a code blue or regular RRT call, which indicate the need for immediate action) and provides an opportunity for spending time with patients without the constraints of an ongoing resuscitation.

We also found that of the patients who triggered an alert, approximately half would have been flagged for a palliative care referral using our own internal screening tool. Furthermore, having longitudinal comorbidity (Comorbidity Point Score, version 2 [COPS2]) and severity of illness (Laboratory-Based Acute Physiology Score, version 2) scores $^{22}$ facilitated the identification of patients who needed review of their preferences with respect to escalation of care. Currently, our primary case-finding criterion for proactive SCT consultation is a COPS2 $>65$, which is associated with a $10.8 \%, 30$-day mortality risk. Overall, the SCT was asked to see about $25 \%$ of patients in whom an alert was triggered.
The workflows we developed were employed at the first site to go live (South San Francisco, 7000 annual discharges, Figure 1) and then modified at Sacramento ( 14,000 annual discharges, Figure 2). Because the hospitals differ in several respects, from size and patient population to staffing, the workflows are slightly different.

The EWS provides deterioration probabilities every 6 hours, and first responders (RRT nurses) intervene when this probability is $\geq 8 \%$. The RRT nurse can activate the clinical response arm, the Respecting Choices pathway, or both. In South San Francisco, which lacked the resources to staff supportive care 24 hours a day/7 days a week, the RRT contacts a medical social worker (MSW) who performs an immediate record review. If this identifies something meriting urgent communication (eg, conflicting or absent information regarding a patient's surrogate), the MSW alerts the hospitalist. The MSW documents findings and ensures that a regular MSW consult occurs the next day. If the MSW feels the patient needs an SCT consult, the MSW alerts the team (this does not preclude a hospitalist or RRT nurse from initiating SCT consultation). At the Sacramento site, where the SCT team is staffed 24 hours a day/7 days a week, it is possible to bypass the MSW step. In addition, each morning the SCT reviews all alerts issued during the previous 24 hours to determine if an SCT consult is needed. In addition, the SCT also proactively reviews the COPS2 scores on all admissions to identify patients who could benefit from an SCT consult. Although surrogate identification and clarifying goals of care are essential, the SCT also helps patients in other ways, as is evident from the following case studies.

The major difference between the palliative care team and the SCT is that the SCT includes the inpatient social worker as part of the team. The SCT has a more focused role (its efforts center on aligning patient goals and priorities with the care that will actually be provided). In contrast, the palliative care team has other functions (eg, pain and symptom management) that are not necessarily associated with life care planning or the alert response.

Considerable overlap exists between patients who trigger an alert and those who would have met screening criteria established prior to EWS deployment. Although this is evolving, we can say that, in general, both sites are moving to an "or" criterion for involving the SCT (patient meets traditional criteria of the screening tool or triggers alert). Further, as KPNC begins adding more sites to the system, serious consideration is being given to only employing the COPS2 score as the primary screening criterion.

\section{CASE STUDY 1: SURROGATE IDENTIFICATION}

Mr. Smith, a 78-year-old man with congestive heart failure $(\mathrm{CHF})$, atrial fibrillation, severe chronic obstructive pulmonary disease, and history of stroke, was admitted due to CHF exacerbation. The morning 


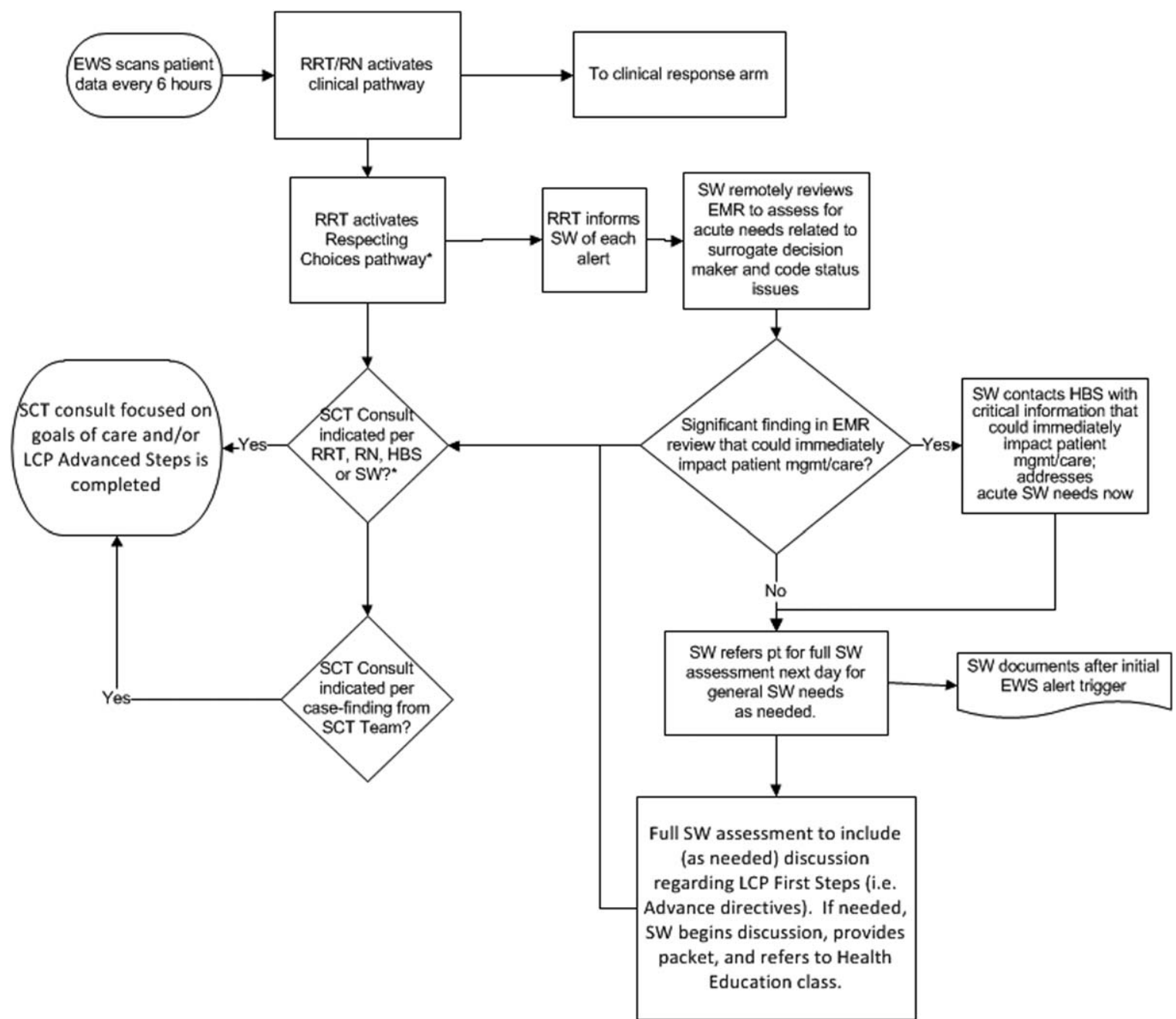

FIG. 1. Workflow for integrating Respecting Choices model with a real-time early warning system at Kaiser Permanente South San Francisco. See text for additional details. Abbreviations: EWS, early warning system, EMR, electronic medical record; pt, patient; LCP, life care planning; HBS, hospital based specialist; $\mathrm{RN}$, registered nurse; RRT, rapid response team; SCT, supportive care team; SW, social worker.

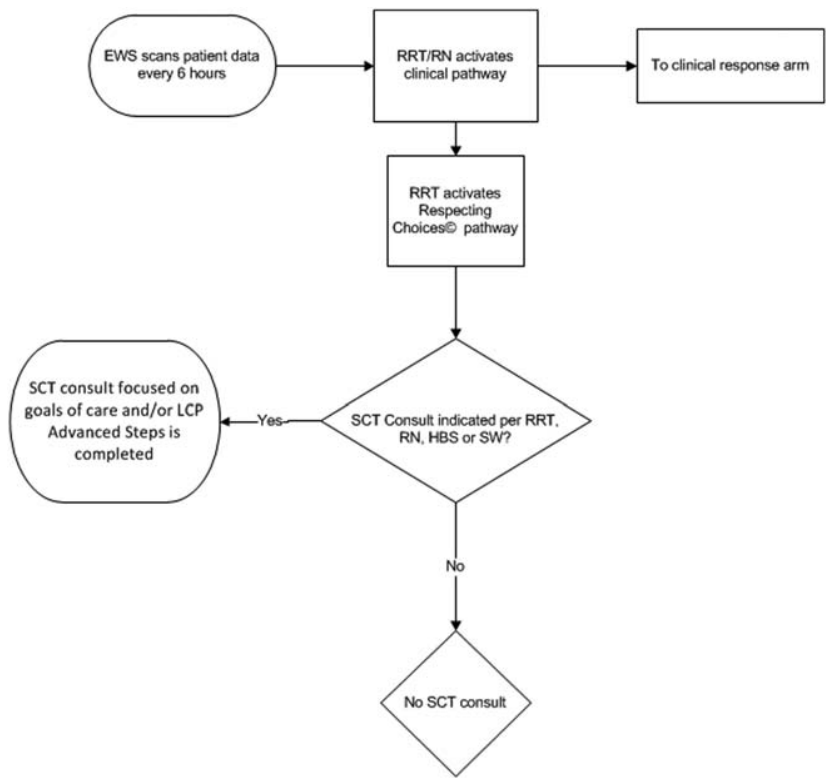

FIG. 2. Workflow for integrating Respecting Choices model with a real-time early warning system at Kaiser Permanente Sacramento. See text for additional details. Abbreviations: EWS, early warning system, EMR, electronic medical record; RN, registered nurse; RRT, rapid response team; SCT, supportive care team. after admission, he experienced uncontrolled tachycardia associated with low oxygen saturation, triggering an alert. The hospitalist stabilized him and documented the treatment plan as follows: "If worsening signs (shortness of breath/wheezing) or decreased saturation on current oxygen supplement, check chest film and arterial blood gas chest $\mathrm{x}$-ray/ arterial blood gas and call MD for possible bilevel positive airway pressure and repeating the echo. Intensive care unit (ICU) transfer as needed." According to his sister, his resuscitation preference was full code.

Given the new protocol instituted since the deployment of the EWS, the MSW reviewed the chart and found that the patient's sister, who lived locally and was the emergency contact, had been incorrectly identified as the surrogate. In a prior hospitalization, Mr. Smith had named his brother as his surrogate, as the patient felt strongly that his sister would not make good decisions for him. The following day, the SCT met with Mr. Smith, who articulated his desire to change his care directive to DNR. He also asked for a full palliative consult when his brother could come in (3 days later). 
During the consult, his brother learned, for the first time, exactly what heart failure was, and what to anticipate over the next months and years. The 2 brothers completed an advance directive granting Mr. Smith's brother a durable power of attorney including a request for a palliative approach to end-stage illness. They also completed a physician order for life sustaining treatment, for DNR and limited intervention. Mr. Smith stated, "When I go, I'm gone," and recalled that his mother and uncle had protracted illnesses, adding that "I don't want to stay alive if I'm disabled like that."

In this example, the SCT was able to identify the correct surrogate and clarify the patient's resuscitation preference. Without SCT, if this patient had deteriorated unexpectedly, the sister would have insisted on treatment that was inconsistent with Mr. Smith's wishes. The interventions as a result of the alert also led the patient and his brother to begin discussing the medical goals of treatment openly and reach understanding about the patient's chronic and progressive conditions.

\section{CASE STUDY 2: TRANSITION TO HOME- BASED HOSPICE}

Mr. North was a 71-year-old man admitted for sepsis due to pneumonia. He had a history of temporal arteritis, systemic lupus erythematosus, prostate cancer, squamous cell lung cancer, and chronic leg ulcers. Delirious at the time of admission, he triggered an alert at $6 \mathrm{Am}$, shortly after admission to the ward. He was hypotensive and was transferred to the ICU.

The SCT reviewed the case and judged that he met criteria for consultation. His wife readily agreed to meet to discuss goals and plan of care. She had been taking care of him at home, and was overwhelmed by his physical needs as well as his worsening memory loss and agitation. She had not been able to bring him to the clinic for almost 2 years, and he had refused entry to the home health nurse. During the palliative consult, $\mathrm{Mr}$. North was lucid enough to state his preference for comfort-focused care, and his desire not to return to the hospital. Mrs. North accepted a plan for home hospice, with increased attendant care at home.

This case illustrates the benefit of the EWS in identifying patients whose chronic condition has progressed, and who would benefit from a palliative consult to clarify goals of care. Practice variation, the complexity of multiple medical problems, and the urgency of the acute presentation may obscure or delay the need for clarifying goals of care. A structured approach provided by the EWS workflow, as it did in this case, helps to ensure that these discussions are occurring with the appropriate patients at the appropriate times.

\section{CASE STUDY 3: RESOLVING MD-TO-MD MISCOMMUNICATION}

Mr. Joseph was an 89-year-old male hospitalized for a hip fracture. He had a history of atrial fibrillation, prostate cancer with bone metastases, radiation- induced lung fibrosis, stroke, and advanced dementia. His initial admission order was DNR, but this was changed after surgery to full code and remained so. The next few days were relatively uneventful until the alert triggered. By then, the hospitalist attending him had changed 3 times. The social worker reviewed $\mathrm{Mr}$. Joseph's records and determined that a palliative consult had taken place previously at another Kaiser Permanente facility, and that the prior code status was DNR. Although Mr. Joseph's admission care directive was DNR, this was switched to full code for surgery. However, the care directive was not changed back, nor was a discussion held to discuss his preference in case of a complication related to surgery. Meanwhile, he was having increasing respiratory problems due to aspiration and required noninvasive ventilation.

Consequently, the SCT reviewed the alerts from the previous 24 hours and determined that further investigation and discussion were required. When the hospitalist was called, the SCT discovered that the hospitalist had assumed the change to full code had been made by 1 of the previous attending physicians; he also informed the SCT that Mr. Joseph would likely need intubation. The SCT decided to go see the patient and, on approaching the room, saw Mr. Joseph's son waiting outside. The son was asked how things were going, and replied, "We all knew that 1 day he would deteriorate, we just want to make sure he is comfortable." Clearly, the full code status did not reflect the Mr. Joseph's wishes, so this was clarified and the hospitalist was called immediately to change the care directive. The SCT met with the man's son and wife, educating them about aspiration and what to expect. They definitely wished a gentle approach for Mr. Joseph, and it was decided to continue current care, without escalation, until the morning. This was to allow the other son to be informed of his father's condition and to see if his status would improve. The next morning the SCT met with the family at the room, and the patient was placed on comfort measures.

This case illustrates 3 points. One, Mr. Joseph's status was changed to full code during surgery without addressing his preferences should he develop a complication during the postoperative period. Two, when the hospitalist saw the full code order in the electronic record, it was assumed someone else had had a discussion with the patient and his family. Lastly, although a social worker performed a chart review, the full picture only emerged after the entire SCT became involved. Therefore, even in the presence of an EWS with associated protocols, important details can be missed, highlighting the need to build redundancy into workflows.

\section{CASE STUDY 4: RELUCTANCE TO INVOLVE PALLIATIVE CARE TEAM}

Mrs. Wood, a bed-bound 63-year-old with end-stage heart failure, was admitted to the hospital with respiratory failure. She had met with a life care planning facilitator as well as a palliative physician previously but refused to 
TABLE 1. Matched Analyses of Six Supportive Care Quality Measures

\begin{tabular}{|c|c|c|c|c|c|c|c|}
\hline Hospital $^{*}$ & 1 & 2 & $1+2$ combined & Remaining 19 & $P(1)$ & $\mathrm{P}(2)$ & $P(1+2)$ \\
\hline N & 73 & 74 & 147 & 146 & - & - & - \\
\hline Age (y) & $69.3 \pm 14.4$ & $66.4 \pm 15.3$ & $67.8 \pm 14.8$ & $67.4 \pm 14.7$ & 0.37 & 0.62 & 0.82 \\
\hline Male (\%) & $39(53.4 \%)$ & $43(58.1 \%)$ & $82(55.8 \%)$ & $82(56.2 \%)$ & 0.70 & 0.78 & 0.95 \\
\hline Deterioration risk (\%).... & $20.0 \pm 14.3$ & $17.4 \pm 11.6$ & $18.7 \pm 13.0$ & $18.8 \pm 13.6$ & 0.54 & 0.44 & 0.94 \\
\hline LAPS2 $^{\circ}$ & $113 \pm 38$ & $102 \pm 39$ & $107 \pm 39$ & $107 \pm 38$ & 0.28 & 0.38 & 0.9 \\
\hline COPS2 $\square$ & $69 \pm 52$ & $66 \pm 52$ & $67 \pm 52$ & $66 \pm 51$ & 0.75 & 1.00 & 0.85 \\
\hline $\operatorname{Died}(\%) \mathbf{I}$ & $17(23.3 \%)$ & $15(20.3 \%)$ & $32(21.8 \%)$ & $24(16.4 \%)$ & 0.22 & 0.48 & 0.25 \\
\hline Agent identified prior $\mathbf{N}$ & $28(38.4 \%)$ & $18(24.3 \%)$ & $46(31.3 \%)$ & $21(14.4 \%)$ & $<0.001$ & 0.07 & 0.001 \\
\hline Agent identified after\# & $46(63.0 \%)$ & $39(52.7 \%)$ & $85(57.8 \%)$ & $28(19.4 \%)$ & $<0.001$ & $<0.001$ & $<0.001$ \\
\hline Updating within 24 hours** & $32(43.8 \%)$ & $45(60.8 \%)$ & $77(52.4 \%)$ & $59(40.4 \%)$ & 0.63 & 0.00 & 0.04 \\
\hline Goals of care discussion...... & $20(27.4 \%)$ & $37(50.0 \%)$ & $57(38.8 \%)$ & $32(21.9 \%)$ & 0.37 & 0.001 & 0.002 \\
\hline Palliative care consultoo & $19(26.0 \%)$ & $49(66.2 \%)$ & $68(46.3 \%)$ & $35(24.0 \%)$ & 0.74 & $<0.001$ & $<0.001$ \\
\hline Spiritual support offered & $27(37.0 \%)$ & $30(40.5 \%)$ & 57 (38.8\%) & $43(29.4 \%)$ & 0.26 & 0.10 & 0.09 \\
\hline
\end{tabular}

NOTE: *See text for additional details. The patients at the remaining 19 hospitals were identified based on their retrospective (virtual) deterioration probabilities and then matched to the patients at the pilot sites. The matching algorithm specified exact matches for these variables: alert threshold reached or not; sex; Kaiser Permanente membership status; had the patient been in the intensive care unit prior to the first alert; and care directive prior to the alert (full code vs not full code). Once potential matches were found using the above, the algorithm found the closest match for the following variables: deterioration probability, age, comorbidity burden, and admission illness severity. Statistical comparisons are as follows: $P(1)$ : $P$ value for comparison of pilot hospital 1 versus remaining 19 Kaiser Permanente Northern California hospitals; $P(2)$, as per $P(1)$, but for pilot hospital 2; $P(1+2)$, both pilot hospitals' data combined. For continuous variables, numbers shown are mean \pm standard deviation. Numbers in bold italics are those that were significantly different. ...Deterioration risk is generated by the early warning system. It is the probability that a patient will require transfer to the intensive care unit within the next 12 hours. Interventions are initiated when this risk is $>8 \%$. ${ }^{\circ}$ LAPS2 = admission Laboratory-based Acute Physiology Score, version 2 ; measure of acute instability where the higher the score, the greater the degree of physiologic derangement. Patients with LAPS2 $>110$ are very unstable. See citation 20 for additional details. $\square$ COPS2 = Comorbidity Point Score, version 2; measure of chronic disease burden over preceding 12 months that is assigned to all Kaiser Permanente Northern California members on a monthly basis. The higher the score, the greater the chronic illness burden. Patients with COPS2 $\geq 65$ have a significant comorbid illness burden. See citation 20 for additional details. IRefers to 30 day mortality. ÑIndicates whether documentation preceding an alert clearly specified who the patient's agent (decision-maker or surrogate) was. \#lndicates whether documentation immediately following an alert clearly specified who the patient's agent (decision-maker or surrogate) was. * Refers to whether chart documentation indicated that the patient's family or agent were updated about the patient's condition within 24 hours after an alert. .......Refers to whether chart documentation indicated that a discussion occurred regarding the patient's goals of care occurred within 24 hours after an alert. ${ }^{\circ}$ Indicates whether a palliative care consultation occurred within 24 hours after an alert.

discuss end-of-life options. She felt she would always do well and her husband felt the same way. During this admission a routine palliative referral was made, but she and her husband refused. The chaplain visited often and then the patient took a turn for the worse, triggering an alert and was transferred to the ICU.

The hospitalist did not feel a SCT consult was indicated based on prior discussions. However, the SCT reviewed the records and felt an intervention was needed. The patient, now obtunded, had worsening renal failure and required continuous pressor infusions. The chaplain spoke with Mr. Wood, who felt a consult was appropriate. Mrs. Wood was no longer able to make decisions, and her husband needed more information about what to expect. At the end of the discussion, he decided on comfort care, and his wife expired peacefully in the hospital.

This case illustrates that, although initially the primary attending may feel a palliative consult is not helpful and possibly detrimental to the patient's care under usual circumstances, decisions may change as the patient's condition changes. The EWS alert helped the SCT recognize the drastic change in the patient's condition and the need to support the patient's family. The family had been resistant, but the SCT was able to help the family transition to a palliative approach with its gentle contact and being clear about its role to provide support regardless of their decision.

\section{CASE STUDY 5: ALERT FACILITATES TRANSITION TO OUTPATIENT PALLIATIVE CARE}

Mr. Jones was an 82-year-old gentleman who had a recent episode of gastrointestinal bleeding while on vacation. He was transferred by air ambulance to the hospital and developed delirium and agitation. His evaluation revealed that he had polycythemia vera and a recently made diagnosis of mild dementia.

In this case, the SCT reviewed the chart not because of an alert, but because the hospitalist noted that $\mathrm{Mr}$. Jones had a very high severity of illness score on admission. When the SCT arrived at Mr. Jones's room, 3 family members were present. His wife appeared to be very frail and was too emotional to make decisions. The children present at the bedside were new to the problems at hand but wanted to help. The SCT team educated the family about his current disease state, the general disease trajectory, and what to expect. They explored the patient's values and any indicators of what his care preference would be if he could communicate it. The SCT established a life care plan at that visit. Based upon Mr. Jones's own wishes and values, he was made DNR with limited interventions. He survived the hospitalization and was followed by the outpatient palliative care clinic as well as by hematology.

This case illustrates 2 facets: a high severity of illness score led to consultation even without an alert. Following this, the SCT could take on a taskarriving at a life care plan by exploring values-that is difficult and time consuming for a busy hospitalist. It also illustrates that patients may elect to obtain other options, in this case, outpatient palliative care.

\section{FUTURE DIRECTIONS}

Our team has also started a quantitative evaluation process. The major limitation we face in this effort is that, unlike physiologic or health services measures (eg, 
tachycardia, hospital length of stay, mortality), the key measures for assessing the quality of palliative and endof-life care need to be extracted by manual chart review. Our approach is based on the palliative and end-of-life care measures endorsed by the National Quality Forum, ${ }^{23}$ which are described in greater detail in the appendix. As is the case with other outcomes, and as described in the article by Escobar et al., ${ }^{21}$ we will be employing a difference-in-differences approach as well as multivariate matching ${ }^{24-26}$ to evaluate effectiveness of the intervention. Because of the high costs of manual chart review, we will be reviewing randomly selected charts of patients who triggered an alert at the 2 pilot sites as well as matched comparison patient charts at the remaining $19 \mathrm{KPNC}$ hospitals. Table 1 provides preliminary data we gathered to pilot the brief chart review instrument that will be used for evaluating changes in supportive care in the regional rollout. Data are from a randomly selected cohort of 150 patients who reached the alert threshold at the 2 pilot sites between November 13, 2013 and June 30, 2014. After removing 3 records with substantial missing data, we were able to find 146 matched patients at the remaining 19 KPNC hospitals during the same time period. Matched patients were selected from those patients who had a virtual alert based on retrospective data. Table 1 shows that, compared to the other KPNC hospitals, the quality of these 6 aspects of supportive care was better at the pilot sites.

\section{CONCLUSION}

Although we continue to review our care processes, we feel that our overall effort has been successful. Nonetheless, it is important to consider a number of limitations to the generalizability of our approach. First, our work has taken place in the context of a highly integrated care delivery system where both information transfer as well as referral from the inpatient to the outpatient setting can occur easily. Second, because the pilot sites were among the first KPNC hospitals to begin implementing the Respecting Choices model, they undoubtedly had less ground to cover than hospitals beginning with less infrastructure. Third, because of resource limitations, our ability to capture process data is limited. Lastly, both sites were able to obtain resources to expand necessary coverage, which might not be possible in many settings.

In conclusion, we made a conscious decision to incorporate palliative care into the planning for the deployment of the alert system. Further, we made this decision explicit, informing all caregivers that providing palliative care that adheres to the Respecting Choices model would be essential. We have found that integration of the SCT, the EWS, and routine hospital operations can be achieved. Clinician and patient acceptance of the Respecting Choices component has been excellent. We consider 3 elements to be critical for this process, and these elements form an integral component of the expansion of the early warning system to the remaining 19 KPNC hospitals. The first is careful planning, which includes instructing RRT first responders on their role in the process of ensuring the respect of patient preferences. Second, having social workers available 24 hours a day/7 days a week as backup for busy hospitalists, is essential. Finally, as is described by Dummett et al., ${ }^{27}$ including reminders regarding patient preferences in the documentation process (by embedding it in an automated note template) is also very important.

\section{Acknowledgements}

The authors thank Dr. Michelle Caughey, Dr. Philip Madvig, Dr. Patricia Conolly, Ms. Barbara Crawford, and Ms. Melissa Stern for their administrative support, Dr. Tracy Lieu for reviewing the manuscript, and Ms. Rachel Lesser for formatting the manuscript.

Disclosures: This work was supported by a grant from the Gordon and Betty Moore Foundation (Early Detection, Prevention, and Mitigation of Impending Physiologic Deterioration in Hospitalized Patients Outside Intensive Care: Phase 3, pilot), The Permanente Medical Group, Inc., and Kaiser Foundation Hospitals, Inc. As part of our agreement with the Gordon and Betty Moore Foundation, we made a commitment to disseminate our findings in articles such as this one. However, the Foundation played no role in how we actually structured our articles, nor did they review or preapprove any of the manuscripts submitted as part of the dissemination component. None of the other sponsors had any involvement in our decision to submit this manuscript or in the determination of its contents. None of the authors have any conflicts of interest to declare of relevance to this work.

\section{References}

1. Institute of Medicine of the National Academies. Dying in America: Improving Quality and Honoring Individual Preferences Near the End of Life. Washington, DC: Institute of Medicine of the National Academies; 2014.

2. Partners LR. Final chapter: Californians' attitudes and experiences with death and dying. California HealthCare Foundation website. Available at: http://www.chcf.org/publications/2012/02/final-chapterdeath-dying. Published February 2012. Accessed July 14, 2015.

3. Rozenbaum EA, Shenkman L. Predicting outcome of inhospital cardiopulmonary resuscitation. Crit Care Med. 1988;16(6):583-586.

4. Hournihan F, Bishop G., Hillman KM, Dauffurn K, Lee A. The medical emergency team: a new strategy to identify and intervene in highrisk surgical patients. Clin Intensive Care. 1995;6:269-272.

5. Winters BD, Pham J, Pronovost PJ. Rapid response teams-walk, don't run. JAMA. 2006;296(13):1645-1647.

6. Winters BD, Pham JC, Hunt EA, Guallar E, Berenholtz S, Pronovost PJ. Rapid response systems: a systematic review. Crit Care Med. 2007; 35(5):1238-1243.

7. Litvak E, Pronovost PJ. Rethinking rapid response teams. JAMA. 2010;304(12):1375-1376.

8. Jones DA, McIntyre T, Baldwin I, Mercer I, Kattula A, Bellomo R. The medical emergency team and end-of-life care: a pilot study. Crit Care Resusc. 2007;9(2):151-156.

9. Chen J, Flabouris A, Bellomo R, Hillman K, Finfer S. The Medical Emergency Team System and not-for-resuscitation orders: results from the MERIT study. Resuscitation. 2008;79(3):391-397.

10. Vazquez R, Gheorghe C, Grigoriyan A, Palvinskaya T, Amoateng-Adjepong Y, Manthous CA. Enhanced end-of-life care associated with deploying a rapid response team: a pilot study. J Hosp Med. 2009;4(7):449-452.

11. Knott CI, Psirides AJ, Young PJ, Sim D. A retrospective cohort study of the effect of medical emergency teams on documentation of advance care directives. Crit Care Resusc. 2011;13(3):167-174.

12. Coventry C, Flabouris A, Sundararajan K, Cramey T. Rapid response team calls to patients with a pre-existing not for resuscitation order. Resuscitation. 2013;84(8):1035-1039.

13. Downar J, Barua R, Rodin D, et al. Changes in end of life care 5 years after the introduction of a rapid response team: a multicentre retrospective study. Resuscitation. 2013;84(10):1339-1344.

14. Smith RL, Hayashi VN, Lee YI, Navarro-Mariazeta L, Felner K. The medical emergency team call: a sentinel event that triggers goals of care discussion. Crit Care Med. 2014;42(2):322-327.

15. Sundararajan K, Flabouris A, Keeshan A, Cramey T. Documentation of limitation of medical therapy at the time of a rapid response team call. Aust Health Rev. 2014;38(2):218-222.

16. Visser P, Dwyer A, Moran J, et al. Medical emergency response in a sub-acute hospital: improving the model of care for deteriorating patients. Aust Health Rev. 2014;38(2):169-176.

17. Respecting Choices advance care planning. Available at: http://www. gundersenhealth.org/respecting-choices. Gundersen Health System website. Accessed March 28, 2015.

18. Escobar G, Dellinger RP. Early detection, prevention, and mitigation of critical illness outside intensive care settings. J Hosp Med. 2016;11:000-000. 
19. Langley GL, Moen R, Nolan KM, Nolan TW, Norman CL, Provost LP. The Improvement Guide: A Practical Approach to Enhancing Organizational Performance. 2nd ed. San Francisco, CA: Jossey-Bass; 2009

20. Nadeem E, Olin SS, Hill LC, Hoagwood KE, Horwitz SM. Understanding the components of quality improvement collaboratives: a systematic literature review. Milbank Q. 2013;91(2):354-394.

21. Escobar G, Turk B, Ragins A, et al. Piloting electronic medical recordbased early detection of inpatient deterioration in community hospitals. I Hosp Med. 2016;11:000-000.

22. Escobar GJ, Gardner M, Greene JG, Draper D, Kipnis P. Risk-adjusting hospital mortality using a comprehensive electronic record in an integrated healthcare delivery system. Med Care. 2013;51(5):446-453.

23. Department of Health and Human Services. Palliative care and endof-life care-a consensus report. National Quality Forum website.
Available at: http://www.qualityforum.org/projects/palliative_care_ and end-of-life care.aspx. Accessed April 1, 2015.

24. Gu XS, Rosenbaum PR. Comparison of multivariate matching methods: structures, distances, and algorithms. J Comput Graph Stat. 1993;2(4):405-420.

25. Feng WW, Jun Y, Xu R. A method/macro based on propensity score and Mahalanobis distance to reduce bias in treatment comparison in observational study: Eli Lilly working paper. Available at: http:// www.lexjansen.com/pharmasug/2006/publichealthresearch/pr05.pdf. Accessed January 24, 2013.

26. Stuart EA. Matching methods for causal inference: a review and a look forward. Stat Sci. 2010;25(1):1-21.

27. Dummett BA, Adams C, Scruth E, Liu V, Guo M, Escobar G. Incorporating an early detection system into routine clinical practice in two community hospitals. J Hosp Med. 2016;11:000-000.

\section{APPENDIX 1}

\section{Key measures to assess the quality of supportive care extracted by manual chart review}

\begin{tabular}{|c|c|c|c|}
\hline Chart review question & Outcome desired & Outcome measured & $\begin{array}{c}\text { Rationale for selecting this } \\
\text { outcome }\end{array}$ \\
\hline $\begin{array}{l}\text { Was the patient's decision-maker } \\
\text { documented following the alert? } \\
\text { If yes: } \\
\text { Time/date of documentation. }\end{array}$ & $\begin{array}{l}\text { Timely identification and documentation of } \\
\text { the patient's decision-maker immedi- } \\
\text { ately following the alert }\end{array}$ & $\begin{array}{l}\text { Whether the patient's decision-maker was } \\
\text { clearly identified and documented by a } \\
\text { member of the treatment team (nurse, } \\
\text { physician, and/or rapid response team) } \\
\text { following the alert. } \\
\text { This outcome is measured independently of } \\
\text { whether the patient's decision-maker } \\
\text { was already documented prior to the } \\
\text { alert. }\end{array}$ & $\begin{array}{l}\text { Clear documentation facilitates the } \\
\text { notification of a patient's family/ } \\
\text { decision-maker in a timely manner } \\
\text { to enhance communication and } \\
\text { clinical decision-making to make } \\
\text { sure that the patient's wishes and } \\
\text { preferences are honored. }\end{array}$ \\
\hline $\begin{array}{l}\text { Was the patient's decision-maker/family } \\
\text { notified or was there an attempt to notify } \\
\text { the patient's decision-maker regarding the } \\
\text { changes in the patient's condition following } \\
\text { the alert? } \\
\text { If yes: } \\
\text { Time/date of notification/attempted contact. }\end{array}$ & $\begin{array}{l}\text { Providing patient's family members/deci- } \\
\text { sion-maker with an update in the } \\
\text { patient's clinical condition following the } \\
\text { alert }\end{array}$ & $\begin{array}{l}\text { Whether the medical team notified or } \\
\text { attempted to contact the patient's fami- } \\
\text { ly/decision-maker to provide an update } \\
\text { in the patient's clinical condition follow- } \\
\text { ing the alert. }\end{array}$ & $\begin{array}{l}\text { Providing timely updates when a } \\
\text { patient's clinical status changes } \\
\text { enhances communication and helps } \\
\text { to proactively involve patients and } \\
\text { families in the decision-making } \\
\text { process. }\end{array}$ \\
\hline $\begin{array}{l}\text { Was there a goals of care discussion fol- } \\
\text { lowing the alert? } \\
\text { If yes: } \\
\text { Time/date of discussion }\end{array}$ & $\begin{array}{l}\text { To clarify and to honor individual patient's } \\
\text { goals of care }\end{array}$ & $\begin{array}{l}\text { Whether a "goals of care" discussion was } \\
\text { initiated after the alert was issued. Cri- } \\
\text { teria for "Goals of Care" discussion } \\
\text { included any/all of the following: } \\
\text { - Specific language in the documentation } \\
\text { that stated verbatim "Goals of Care } \\
\text { Discussion" } \\
\text { - Providing prognosis and treatment } \\
\text { options; eliciting preferences; AND doc- } \\
\text { umenting decisions made and preferen- } \\
\text { ces as a result of the discussion. }\end{array}$ & $\begin{array}{l}\text { Goals of care discussions actively } \\
\text { involve patients and families in the } \\
\text { decision-making process to ensure } \\
\text { that their wishes and preferences } \\
\text { are clearly documented and } \\
\text { followed. }\end{array}$ \\
\hline $\begin{array}{l}\text { Was there a palliative care consultation } \\
\text { during the patient's hospitalization? }\end{array}$ & $\begin{array}{l}\text { To provide comprehensive supportive care } \\
\text { to patients and their families/loved } \\
\text { ones. }\end{array}$ & $\begin{array}{l}\text { Whether palliative care was consulted dur- } \\
\text { ing the patient's hospitalization }\end{array}$ & $\begin{array}{l}\text { The palliative care team plays an } \\
\text { important role in helping patients/ } \\
\text { families make decisions, providing } \\
\text { support, and ensuring that patients' } \\
\text { symptoms are addressed and prop- } \\
\text { erly managed }\end{array}$ \\
\hline $\begin{array}{l}\text { Was spiritual support offered to the } \\
\text { patient and/or their family/loved } \\
\text { during the patient's hospitalization? }\end{array}$ & $\begin{array}{l}\text { To offer and to provide spiritual support to } \\
\text { patients and their families/loved ones }\end{array}$ & $\begin{array}{l}\text { Whether the patientffamily was offered } \\
\text { spiritual support during the patient's } \\
\text { hospitalization }\end{array}$ & $\begin{array}{l}\text { Spiritual support has been recognized } \\
\text { as an important aspect of quality } \\
\text { EOL care }\end{array}$ \\
\hline
\end{tabular}




\section{APPENDIX 2}

\section{Respecting Choices $\subseteq$, A Staged Approach to Advance Care Planning}

Respecting Choices $\bigcirc$ is a staged approach to advance care planning, where conversations begin when people are healthy and continue to occur throughout life.

Our Life Care Planning service consists of three distinct steps.

1. My Values: First Steps is appropriate for all adults, but should definitely be initiated as a component of routine healthcare for those over the age of 55. The goals of First Steps are to motivate individuals to learn more about the importance of Life Care Planning, select a healthcare decision maker, and complete a basic written advance directive.

2. My Choices: Next Steps is for patients with chronic, progressive illness who have begun to experience a decline in functional status or frequent hospitalizations. The goals of this stage of planning are to assist patients in understanding a) the progression of their illness, b) potential complications, and c) specific life-sustaining treatments that may be required if their illness progresses. Understanding life-sustaining treatments includes each treatment's benefits, burdens, and alternatives. With this understanding members will be better able to express what situations (e.g. complications or bad outcomes) would cause them to want to change their plan of care. Additionally, the individual's healthcare agent(s) and other loved ones are involved in the planning process so that they can be prepared to make decisions, if necessary, and to support the plan of care developed.

3. My Care: Advanced Steps is intended for frail elders or others whose death in the next 12 months would not be surprising. It helps patients and their agent make specific and timely life-sustaining treatment decisions that can be converted to medical orders to guide the actions of healthcare providers and be consistent with the goals of the individual.

(Reference: http://www.gundersenhealth.org/respecting-choices).

\section{APPENDIX 3}

\section{Pilot site Palliative Care Referral Criteria}

Automatic palliative care consults for adults at Sacramento site are as follows:

1. 30 day readmits or $>3 \mathrm{ED}$ or acute readmissions in past year for $\mathrm{CHF}$ or COPD that have no Advance Directive and are not followed by Chronic Care Management

2. Aspiration

3. CVA with poor prognosis for regaining independence

4. Hip fracture patients not weight bearing on post-operative day 2

5. "Code blue" survivor

6. Skilled Nursing Facility resident with sepsis and or dementia

7. Active hospice patients

8. Sepsis patients with 10 or more ICD codes in the problem list

Potential palliative care consults for adults at Sacramento pilot site are as follows:

1. Morbid obesity complicated by organ damage (e.g., congestive heart failure, refractory liver disease, chronic renal disease)

2. Severe chronic kidney disease and/or congestive heart failure with poor functional status (chair or bed bound)

3. Patient with pre-operative arteriovenous fistulas and poor functional status, congestive heart failure, or age $>80$

4. End stage liver disease with declining functional status, poor odds of transplant 